\title{
MOLECULAR DIAGNOSIS OF ORAL PRE-MALIGNANT LESIONS \& ORAL SQUAMOUS CELL CARCINOMA IN SALIVA-A BREAKTHROUGH IN PAKISTAN.
}

\author{
Iqbal A. Muhammad Khyani, Masood A. Qureshi, M. Umar Farooq \& Talat Mirza \\ Dow University of Health Sciences, Karachi \\ Corresponding Author Email: driqbalkhyani@yahoo.com
}

\begin{abstract}
Objective: To evaluate salivary detection of interleukin $6 \& 8$ and high risk HPV-16 \& 18 are informative biomarkers of Oral Pre-malignant Lesion (PML) and Oral Squamous Cell Carcinoma (OSCC) in our population. Duration: July 2011 to December 2012. Subjects and Methods: Total 105 cases were included. The subjects were divided in three groups 'A', 'B' \& ' $C$ ' having 35 participants each. Group 'A' comprised of patients having strong clinical evidence of oral PML. Group 'B' constitutes histologically proven OSCC and Group ' $\mathrm{C}$ ' includes disease free subjects as controls. Relevant clinical history was recorded after informed consent on institutional approved performa. Saliva was collected as per standard drooling method'. Samples were stored at $+4 \mathrm{oC}$ and later transferred to Dow Diagnostic, Research \& Reference Laboratory to store it at $-20 \mathrm{oC}$ before further process. Samples were subjected to centrifugation at $4500 \mathrm{rpm}$ for 15 minutes at $4 \mathrm{oC}$. Supernatant fluid phase was used in ELISA for detection and quantification of IL6 and IL8. . Cell pellets were used for identification of high risk HPV-16 \& 18 by real-time PCR. Data was entered and analyzed on SPSS version 16. P-value of 0.05 was taken as standard reference. Results: In group 'A', IL6 was not detected in almost all the subjects except one case. IL8 was detected in 26/35 (74.3\%) subjects and not detected in 09 (25.7\%) cases. In group 'B', IL6 was detected in $13(37.1 \%)$ cases and in $22(62.9 \%)$ cases, it cannot be detected. IL8 was detected in $33(94.3 \%)$ and it was not detected in $02(5.7 \%)$ subjects. It is observed that IL8 is consistently found raised in group 'A' \& 'B'. In group 'C', IL6 was not detected in any of the subject while IL8 was detected in $10(28.6 \%)$ cases. Significant association was found for qualitative salivary detection of IL6 and IL8 between the groups $(\mathrm{P}=<0.0001$ and $<0.0001$ respectively). Regarding quantitative salivary concentration of IL6 \& IL8, no significant co-relation was found in salivary levels of IL6 between the groups while there was significant association of salivary IL8 levels between the groups $(\mathrm{P}=<0.0001)$. On post Hoc multiple comparison, significant co-relation was found in IL8 levels between oral PML group and controls $(\mathrm{P}=0.001)$ and OSCC group and controls $(\mathrm{P}=<0.0001)$. In group 'A', HPV-16 was detected in salivary samples of $3(8.6 \%)$ cases while HPV-18 was not detected. In group 'B', HPV-16 was detected in the salivary samples of $07(20 \%)$ cases while HPV-18 was detected in $06(17.1 \%)$ cases. Mixed HPV-16 and HPV-18 were found in $02(5.7 \%)$ cases. In group ' $\mathrm{C}$ ', HPV-16 was detected in 03(8.6\%) cases while HPV-18 was not detected in any of the subjects. Significant relationship was observed between the groups for salivary HPV-18 detection $(\mathrm{P}=0.002)$ while for detection of HPV-16, no significant association was found $(\mathrm{P}=0.245)$. Conclusion: Salivary concentration of IL6 and IL8 in oral PML and oral cancer are useful biomarkers in our population. Detection of HPV infection for the causation of oral cancer cannot be fully established possibly due to small sample size. More over different genetic makeup, environmental and geographic differences, indulgence in peculiar risk factor habits and different sexual practices compared to west due to socio-cultural and religious restrictions could be the reason.
\end{abstract}

KEYWORDS

Interleukins, Human papilloma virus, Pre-malignant lesions, Oral squamous cell carcinoma, Molecular diagnosis, Salivary diagnosis.

\section{INTRODUCTION}

Oral cancer is reported sixth most frequently occurring malignancy all over the world (Jemal, 2010). The burden of oral cancer is much higher in developing countries compared to Western countries. This carcinoma accounts for almost $40 \%$ of all cancers in the Indian subcontinent and contributed one-third of the world burden of oral cancer (Mehrotra, 2006; Ahluwalia, 2005; Ahluwalia, 2005).

Carcinoma of oral cavity is the second most common malignant tumor for both the gender in Pakistan (Bhurgri, 2000). It constitutes $20-35 \%$ of all cancers presented to public hospitals in Karachi and slightly less in other regions of Pakistan. Never the less it is a major killer in our population (Bhurgri, 2005).
Multiplicative effects of nutritional deficiency, dietary habits, bad oral hygiene, mal-directed sharp, gagged teeth and infection with human papilloma virus (HPV) has been implemented in oral carcinogenesis. In Pakistan, the major risk factors are areca nut (betel nut, chalia, supari), betel quid (paan), tobacco chewing, naswar, paan masala (ghutka, mawa) and poor nutrition. Due to religious restrictions, alcohol consumption and sexual promiscuity are not a prevalent habits in Karachi.

Pro-inflammatory, pro-angiogenic cytokines such as Tumor

Necrosis Factor-Alpha (TNF $\propto$ ), interleukin $\left(\mathrm{IL}_{6} \& \mathrm{IL}_{8}\right)$ were found raised in PML and OSCC. These cytokines are produced in a dysregulated fashion and they have roles in tumourogenesis, cell growth, invasion, interruption of tumor suppression, immune status and even survival (Katakura, 2007; Duffy, 2008; Sato, 2010; Brailo, 2012; Wong, 2006). Causative relationship between human papilloma virus and SCC of the head and neck was suggested. This 
association is more established recently, as HPV-16 \& 18 was the frequently detectable virus in salivary samples, serum and biopsy cell blocks of the patients with oral PML \& OSCC.

Diagnosis and subsequent therapeutic intervention is based on clinical examination, location, stage and histopathological features. Histological examination remains the gold standard for diagnosis and identification of malignant oral lesions. Biopsy is an invasive technique with surgical implications, technique limitations for professionals and psychological implications for most patients. In recent decades there is paradigm shift from histopathology to molecular diagnosis. Identification of high risk oral PML and intervention at this stage constitute one of the keys for reducing the mortality, morbidity and cost of treatment associated with advanced OSCC.

Recently saliva has been utilized as prospective source in molecular diagnostics. Oral fluid meets the demand for noninvasive, easily accessible bio-fluid of human body that exhibits a wide spectrum of biological analytes, informative for clinical diagnostic application.

In Pakistan, saliva is not explored as a diagnostic medium to detect biomarkers for PMLs and OSCC. We detected and estimated cytokines $\mathrm{IL}_{6}$ and $\mathrm{IL}_{8}$ levels and high risk HPV-16 \& 18 in saliva. In this study, we analyzed the application of saliva as a diagnostic fluid for the possibility of early detection of OSCC by these biomarkers in our etiologically distinct population.

\section{SUBJECTS \& METHODS}

This non-interventional, case control study was carried out at department of ENT, Dow University of Health Sciences, Dow Medical College and Civil Hospital Karachi, Pakistan from July 2011 to December 2012.

Patients visiting with any age, sex or ethnic group having strong clinical evidence of pre-malignant lesions, biopsy proven, untreated OSCC at any stage and identical disease free subjects willing to participate as controls, were included in the study. Those who did not turned up with histopathology report or having inconclusive report, subjects with prior history of treatment for loco-regional or distant malignancy and those with history of immune deficiency or autoimmune disorders were excluded.

The participants were divided in three groups 'A', 'B' \& ' $\mathrm{C}$ ' having 35 subjects in each. Group' $A$ ' includes patients having strong clinical evidence of PML. Group ' $\mathrm{B}$ ' constitutes histologically proven untreated OSCC and Group ' $\mathrm{C}$ ' comprised disease free subjects as controls. Relevant clinical history was recorded on institutional approved performa after taking informed consent. Saliva from all subjects was collected as per standard drooling method. Samples were stored at $+4^{\circ} \mathrm{C}$ and later transferred to Dow Diagnostic, Research \& Reference Laboratory to stored it at $-20^{\circ} \mathrm{C}$ before further process. Samples were subjected to centrifugation at $4500 \mathrm{rpm}$ for 15 minutes at $4^{\circ} \mathrm{C}$. The supernatant fluid phase was used in ELISA for detection and quantification of $\mathrm{IL}_{6} \& \mathrm{IL}_{8}$. Cell pellets sediments were used for identification of high risk HPV-16 \& 18 by Real-time PCR method

\section{Elisa for quantification of cytokines $\left(\mathrm{il}_{6}\right.$ and $\left.\mathrm{il}_{8}\right)$ in saliva}

Human, Enzyme linked Immuno Sorbent Assay (ELISA) was performed on supernatant fluid for detection and quantification of cytokines $\mathrm{IL}_{6}$ and $\mathrm{IL}_{8}$ by commercially available kits, Human $\mathrm{S} \mathrm{IL}_{6}$ \& $\mathrm{IL}_{8} / \mathrm{NAP}-1$ Instant ELISA, manufactured by e Bioscience, Bender-Med systems Vienna-Austria. Detection and quantification of cytokines $\mathrm{IL}_{6} \& \mathrm{IL}_{8}$ was carried out in picogram per milliliter $(\mathrm{pg} / \mathrm{ml})$. Average absorbance values for each set of duplicate standards and samples were calculated. Lower limits of detection of $\mathrm{IL}_{6}$ and $\mathrm{IL}_{8}$ were defined and lowest detectable value of $\mathrm{IL}_{6} \&$ $\mathrm{IL}_{8}$ was determined to be $0.92 \mathrm{pg} / \mathrm{ml}$ and $1.3 \mathrm{pg} / \mathrm{ml}$ respectively. Below this level, the concentration was designated as not detected (ND). Standard curve was plotted by mean absorbance of each standard concentration on the ordinate against human $\mathrm{IL}_{6} \& \mathrm{IL}_{8}$ concentration on the abscissa. (Figure-1)

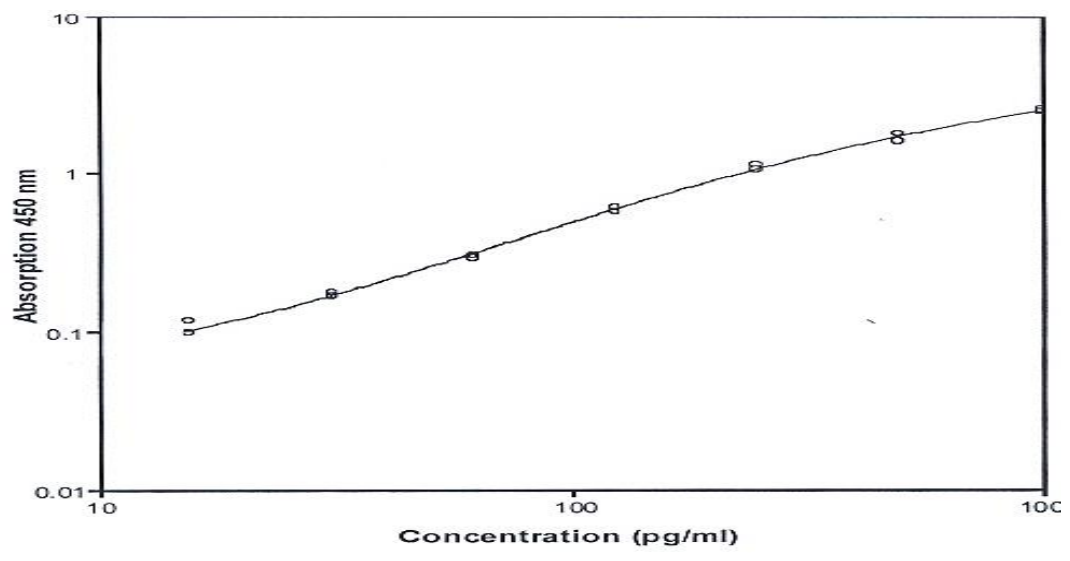

Figure 1: Representative standard curve for $\mathrm{IL}_{6}$ and $\mathrm{IL}_{8}$ Instant ELISA.

To determine the concentration of $\mathrm{IL}_{6} \& \mathrm{IL}_{8}$ in each sample, the mean absorbance value was determined from ordinate and a horizontal line was extended to standard curve. At the point of intersection a vertical line was extended to abscissa and the corresponding value of $\mathrm{IL}_{6} \& \mathrm{IL}_{8}$ was read. As the samples were diluted in ratio of $1: 2$ thus the value read from standard curve was multiplied by dilution factor (X2). 


\section{(A) Principle of assay}

Anti-human $\mathrm{IL}_{6} \& \mathrm{IL}_{8}$ coated antibodies were already adsorbed onto microwells of the commercial kit. Human $\mathrm{IL}_{6} \& \mathrm{IL}_{8}$ present in the salivary samples or standards, binds to antibodies and adsorbed to microwells. Streptavidin-HRP binds to the biotin conjugated anti-human $\mathrm{IL}_{6} \& \mathrm{IL}_{8}$. After incubation, unbound biotin conjugated anti-human $\mathrm{IL}_{6} \& \mathrm{IL}_{8}$ and streptavidin-HRP was removed with washing by substrate solution reactive with HRP. A coloured product was formed in proportion to the amount of soluble human $\mathrm{IL}_{6} \& \mathrm{IL}_{8}$ present in the sample. The reaction was terminated by adding acid and absorbance was measured at $450 \mathrm{~nm}$. A standard curve was prepared from 07 human $\mathrm{IL}_{6} \& \mathrm{IL}_{8}$ standard dilution and concentration of $\mathrm{IL}_{6} \& \mathrm{IL}_{8}$ was determined.

\section{(B) Preparation of reagents}

Wash buffer concentrate $(25 \mathrm{ml})$ vial provided with the kit was poured in clean graduated glass cylinder and $475 \mathrm{ml}$ of distilled water was added and mixed gently to form final $500 \mathrm{ml}$ volume to make dilute wash buffer (Phosphate-buffered saline with $1 \%$ Tween 20).

\section{(C) Test protocol}

Number of microwell strips required to test the desire number of samples plus microwell strips for blanks and standards was determined. Standard strips were placed in position $\left(A_{1} / A_{2}\right.$ to $\left.\mathrm{H}_{1} / \mathrm{H}_{2}\right)$ as per protocol. Distilled water was added in duplicate to all standard, blank and control wells on the plate as indicated on the label. $100 \mu \mathrm{I}$ of distilled water was added to designated sample wells. $50 \mu \mathrm{I}$ of sampled saliva aliquots were added to designated wells. Microwell strips were covered with adhesive film provided and incubated at room temperature $\left(18^{\circ} \mathrm{C}\right.$ to $\left.25^{\circ} \mathrm{C}\right)$ for three hours. Microwell strips washed six times with $400 \mu \mathrm{I}$ of wash buffer solution prepared earlier. After last wash microwell strips tapped on paper towel to remove excess wash buffer. $100 \mu \mathrm{I}$ of TMB substrate solution was added to all wells by micropipette. Microwell strips incubated at room temperature for ten minutes. $100 \mu \mathrm{I}$ of stop solution (phosphoric acid 1M) was added to all wells to stop enzyme reaction, when highest standard dark blue colour developed. Absorbance of each microwell strip was read on a spectrophotometer on $450 \mathrm{~nm}$ wave length to measure the colour intensity. As the samples were diluted 1:2, thus the concentration read from the standard curve was multiplied by the dilution factor (x2).

\section{PCR for identification of high risk hpv-16 \& 18 in saliva}

PCR was used for following purposes;

\section{(A) DNA extraction}

Total DNA was extracted from all the samples using PureLink® Viral RNA/DNA Kits (Invitrogen Life Technologies, Carlsbad USA) for rapid, efficient purification of viral nucleic acids according to the manufacturer's protocol. $12.5 \mu$ l of extracted DNA was used in the HPV genotype analysis using Real-time PCR.

\section{(B) Real-time PCR}

Genotyping of HPV-16 and HPV-18 in isolated DNA from patient's samples were performed on Real-time PCR machine (SmartCycler II, Cepheid, USA) using the Real-time PCR Kit HPV-16/18 Real-TM Quant (Sacace Biotechnologies, Italy).

\section{(i) Principle of assay}

Amplification results of HPV-16 DNA were detected on the FAM/Green channel HPV-18 DNA were detected on the ROX/Orange channel and $\beta$-globin gene used as internal control was detected on the JOE/HEX/Yellow channel.

\section{(ii) Protocol}

Required numbers of tubes were prepared (Number of tests +3 standards and 1 negative control). The extracted DNA samples were added into the tubes with PCR- buffer-FRT $20 \mu 1$ of Hot Start DNA Polymerase and the tubes vertexed carefully. This reaction mixture was carefully shifted to new sterile tubes. $12.5 \mu \mathrm{l}$ of extracted DNA sample was added for each panel and 4 controls were also prepared. $10 \mu \mathrm{l}$ of Quantitative Standards HPV (QS1 HPV, QS2 HPV, and QS3 HPV) was added into 3 labeled tubes. $10 \mu 1$ of DNA-buffer was added to the tube labeled Negative Control.

\section{(iii) Real time amplification}

The tubes were capped and transferred into Real Time Thermal Smart Cycler. The Smart Cycler (Cepheid, USA) instrument was programmed as per manual of instruction. The concentrations of the Quantitative Standards entered in the JOE (Human DNA), FAM (HPV-16) and ROX (HPV-18) channels in order to generate standard curves.

\section{(iv) Data analysis and interpretations}

The software of Smart Cycler Real-time PCR was utilized for the interpretation of results all the way through the presence of crossing of fluorescence curve with the threshold line. Internal control (Human DNA) is detected on the JOE/HEX/Yellow channel, HPV 16 on the FAM/Green channel and HPV 18 on ROX/Orange channel. (Figure-2) 


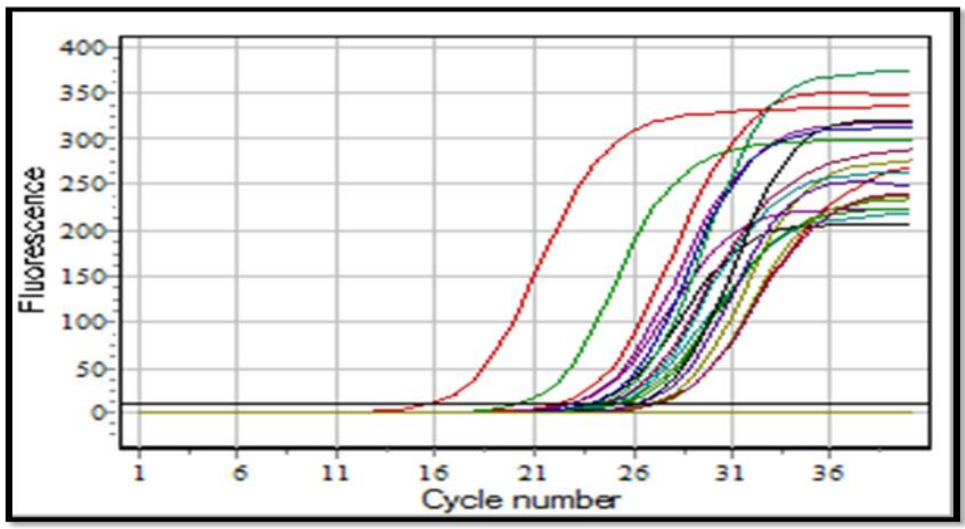

Figure-02: Crossing of fluorescence curves detected in one go; internal control Human DNA) on JOE/HEX/Yellow Channel, HPV-16 on FAM/Green Channel, It HPV-18 on ROX/Orange channel.

Data was entered in computer SPSS version 16 (SPSS Inc. Chicago, IL, USA) Qualitative data was computed to analyse relationship between the groups by applying pearson Chi-Square test. Quantitative data was analysed to look for relationship between the groups by applying Kruskal Wallis One-way ANOVA test. For multiple comparison, between the groups, Post Hoc.2 sided Dunnet $t$ test was applied. P-value of 0.05 was taken as standard value.

\section{RESULTS}

Out of 105 subjects, $70(66.7 \%)$ were males and 35(33.3\%) were females with male/females ratio of $2: 1$. The minimum age of the recruited subjects was 20 years and maximum was 80 years with a mean of 43.2 years. (Table-1)

\begin{tabular}{|l|l|l|l|l|l|l|l|}
\hline \multirow{2}{*}{ Group } & \multirow{2}{*}{$\begin{array}{l}\text { Numbers } \\
\text { of cases }\end{array}$} & \multicolumn{2}{|l|}{ Gender } & \multicolumn{4}{l|}{ Age in Years } \\
\cline { 3 - 8 } & & Male & Female & Minimum & Maximum & Mean $\begin{array}{l}\text { Std. } \\
\text { Deviation }\end{array}$ \\
\hline A & 35 & $25(71.4 \%)$ & $10(28.6 \%)$ & 20.00 & 75.00 & 39.3 & 15.9 \\
\hline B & 35 & $24(68.6 \%)$ & $21(60 \%)$ & 26.00 & 80.00 & 46.7 & 14.4 \\
\hline C & 35 & $21(60 \%)$ & $14(40 \%)$ & 23.00 & 70.00 & 43.5 & 13.7 \\
\hline Total & 105 & $\begin{array}{l}70 \\
(66.7 \%)\end{array}$ & $\begin{array}{l}35 \\
(33.3 \%)\end{array}$ & - & - & - & - \\
\hline
\end{tabular}

Table-1: Gender distribution and age range

In group 'A', majority of the cases $27 / 37$ (77.1\%) were having oral submucosal fibrosis (OSF). Leukoplakia was found in 10(28.6\%) cases. Erythroplakia was detected in $06(17.1 \%)$ cases. All these PMLs were found alone or in combination with other pre- neoplastic lesions. $02(5.7 \%)$ cases were diagnosed clinically as lichen planus alone. (Table-2)

\begin{tabular}{|l|l|l|l|l|}
\hline S.No & Pre-malignant Lesions & Number of Cases & Sites & Number of Cases \\
\hline 1 & $\begin{array}{l}\text { Oral Sub-mucosal } \\
\text { fibrosis }\end{array}$ & $27(77.1 \%)$ & $\begin{array}{l}\text { Cheek, Palate\& } \\
\text { Pillars }\end{array}$ & $27(100 \%)$ \\
\hline 2 & Leukoplakia & $10(28.6 \%)$ & $\begin{array}{l}\text { Cheek/Lip } \\
\text { Tongue }\end{array}$ & $\begin{array}{l}09(90 \%) \\
01(10 \%)\end{array}$ \\
\hline 3 & Erythroplakia & $06(17.1 \%)$ & $\begin{array}{l}\text { Cheek } \\
\text { Tongue }\end{array}$ & $\begin{array}{l}04(66.7 \%) \\
02(33.3 \%)\end{array}$ \\
\hline 4 & Lichen Planus & $02(5.7 \%)$ & $\begin{array}{l}\text { Cheek and } \\
\text { RMT }\end{array}$ & $02(100 \%)$ \\
\hline
\end{tabular}

N.B: The number of cases outnumbered the total as many subjects were having more than one lesion. Table-02: Types \& sites of pre-malignant lesions Group 'A' (n-35) 
In group 'B', cases were staged according to the 2002-3. American Joint Committee on cancer (AJCC) classification. In this 02(5.7\%) cases were $\mathrm{T}_{1}$ stage, $12(34.3 \%)$ were $\mathrm{T}_{2}, 18(51.4 \%)$ were $\mathrm{T}_{3}$ and $03(8.6 \%)$ were $\mathrm{T}_{4}$ stage at presentation. $20(57.1 \%)$ cases were having no clinically palpable nodes $\left(\mathrm{N}_{0}\right), 9(25.7 \%)$ were having $\mathrm{N}_{1}, 05(14.3 \%)$ were having $\mathrm{N}_{2}$ and $01(2.9 \%)$ was having $\mathrm{N}_{3}$ nodal status. Distant metastasis was not found clinically in any of the subjects (Table-3).

\begin{tabular}{|c|c|c|c|c|c|c|c|c|c|c|c|}
\hline \multicolumn{5}{|c|}{$\begin{array}{l}\text { Tumour size ' } T \text { ' } \\
(\mathrm{cms})\end{array}$} & \multicolumn{5}{|c|}{$\begin{array}{l}\text { Cervical nodes ' } \mathrm{N} \text { ' } \\
\text { (Clinical) }\end{array}$} & \multicolumn{2}{|c|}{$\begin{array}{l}\text { Distant } \\
\text { Metastasis } \\
\text { 'M' }\end{array}$} \\
\hline $\mathbf{T}_{1}$ & $\mathbf{T}_{2}$ & $\mathbf{T}_{\mathbf{3}}$ & $\mathbf{T}_{4}$ & Total & $\mathbf{N}_{0}$ & $\mathbf{N}_{1}$ & $\mathbf{N}_{2}$ & $\mathbf{N}_{3}$ & Total & $\mathbf{M}_{0}$ & $\mathbf{M}_{1}$ \\
\hline $\begin{array}{l}02 \\
(5.7 \\
\%)\end{array}$ & $\begin{array}{l}12 \\
(34.3 \\
\%)\end{array}$ & $\begin{array}{l}18 \\
(51.4 \\
\%)\end{array}$ & $\begin{array}{l}03 \\
(8.6 \\
\%)\end{array}$ & $\begin{array}{l}35 \\
(100 \% \\
)\end{array}$ & $\begin{array}{l}20 \\
(57.1 \\
\%)\end{array}$ & $\begin{array}{l}09 \\
(25.7 \\
\%)\end{array}$ & $\begin{array}{l}05 \\
(14.3 \\
\%)\end{array}$ & $\begin{array}{l}01 \\
(2.9 \\
\%)\end{array}$ & $\begin{array}{l}35 \\
(100 \\
\%)\end{array}$ & $\begin{array}{l}35 \\
(100 \\
\%)\end{array}$ & $\begin{array}{l}00 \\
(-)\end{array}$ \\
\hline
\end{tabular}

Table-03: TNM staging of OSCC Group 'B' (n-35)

In group ' $\mathrm{A}$ ', $\mathrm{IL}_{6}$ was not detected in the salivary samples of almost all the subjects except one. $\mathrm{IL}_{8}$ was detected in $26 / 35$ $(74.3 \%)$ and not detected in $09(25.7 \%)$. In group 'B', $\mathrm{IL}_{6}$ was detected in the salivary samples of $13(37.1 \%)$ and in $22(62.9 \%)$ it was not found. $\mathrm{IL}_{8}$ was detected in $33(94.3 \%)$ and it was not detected in $02(5.7 \%)$ subjects. It is observed that $\mathrm{IL}_{8}$ is consistently found raised in group 'A' \& ' $\mathrm{B}$ '. In group ' $\mathrm{C}$ ', $\mathrm{IL}_{6}$ was not detected in any of the subject while $\mathrm{IL}_{8}$ was detected in $10(28.6 \%)$ cases.
Statistical analysis was performed to compare the qualitative relationship between the groups by using Pearson Chi-Square test. Significant association was found between the groups for salivary detection of $\mathrm{IL}_{6}(\mathrm{P}-<0.0001)$. Salivary detection of $\mathrm{IL}_{8}$ was also found to have significant relation between the groups $(\mathrm{P}-<0.0001)$. (Table-04)

\begin{tabular}{|c|c|c|c|c|c|}
\hline \multirow{2}{*}{ Groups } & \multirow{2}{*}{$\begin{array}{l}\text { Number of } \\
\text { Samples } \\
\text { evaluated }\end{array}$} & \multicolumn{2}{|l|}{$\mathrm{IL}_{6}$} & \multicolumn{2}{|l|}{$\mathrm{IL}_{8}$} \\
\hline & & Detected & Not Detected & Detected & Not Detected \\
\hline A & 35 & $01(2.9 \%)$ & $34(97.1 \%)$ & $26(74.3 \%)$ & $09(25.7 \%)$ \\
\hline B & 35 & $13(37.1 \%)$ & $22(62.9 \%)$ & $33(94.3 \%)$ & $02(5.7 \%)$ \\
\hline $\mathrm{C}$ & 35 & 00 & $35(100 \%)$ & $10(28.6 \%)$ & $25(71.4 \%)$ \\
\hline Total & 105 & $14(13.3 \%)$ & $91(86.7 \%)$ & $69(65.7 \%)$ & $36(34.3 \%)$ \\
\hline
\end{tabular}

NB: Non-detectable; Samples measured below the lowest standard point are considered to be non-detectable. Pearson Chi-Square analysis between the groups

$\mathrm{P}$-value $\mathrm{IL}_{6}<0.0001$ - Significant

$\mathrm{P}$-value $\mathrm{IL}_{8}<0.0001$ - Significant

Table-04: Qualitative analysis; salivary detection of cytokines $\mathrm{IL}_{6} \& \mathrm{IL}_{8}$ by ELISA

Quantitative analysis of $\mathrm{IL}_{6} \& \mathrm{IL}_{8}$ was performed between the groups. Over all, the minimum concentration of salivary $\mathrm{IL}_{6}$ detected was $7.9 \mathrm{pg} / \mathrm{ml}$ and maximum was $330.3 \mathrm{pg} / \mathrm{ml}$ with a median value of $77.4 \mathrm{pg} / \mathrm{ml}$. Minimum salivary concentration of $\mathrm{IL}_{8}$ was $2.7 \mathrm{pg} / \mathrm{ml}$ and maximum was $1368.2 \mathrm{pg} / \mathrm{ml}$ with a median value of $472 \mathrm{pg} / \mathrm{ml}$. IL 6 was quantified in only one case of group 'A' while it was not detected in any of group ' $\mathrm{C}$ ' individuals, so further quantitative analysis was not performed.

There were lots of variations in the values of salivary concentration of $\mathrm{IL}_{8}$ quantified. As the numeric data was skewed and unevenly distributed, non-parametric analysis was performed to see the relationship between the groups by applying Kruskal Wallis oneway ANOVA test, which shows significant relationship of concentration of $\mathrm{IL}_{8}$ between the groups $(\mathrm{P}-<0.0001)$. Post Hoc analysis for multiple comparison by two sided, Dunnet.t-test, shows significant association of salivary concentration of $\mathrm{IL}_{8}$ between oral PML group and controls(P- 0.001) and OSCC group and controls $(\mathrm{P}-<0.0001)($ Table-05). 


\begin{tabular}{|c|c|c|c|c|c|c|c|}
\hline \multirow{2}{*}{$\begin{array}{l}\text { Grou } \\
\mathrm{p}\end{array}$} & \multirow{2}{*}{$\begin{array}{l}\text { No. of } \\
\text { Sampl } \\
\text { es }\end{array}$} & \multicolumn{3}{|c|}{$\mathrm{IL}_{6}(\mathrm{Pg} / \mathrm{ml})$} & \multicolumn{3}{|c|}{$\mathrm{IL}_{8}(\mathrm{Pg} / \mathrm{ml})$} \\
\hline & & Minimum & Maximum & Median & Minimum & Maximum & Median \\
\hline A & 35 & 217.8 & 217.8 & 217.8 & 2.7 & 1143.2 & 305.0 \\
\hline B & 35 & 7.9 & 330.3 & 61.2 & 26.9 & 1368.2 & 873.6 \\
\hline $\mathrm{C}$ & 35 & ND & ND & ND & 23.5 & 108.6 & 52.1 \\
\hline
\end{tabular}

Kruskal Wallis, One-way ANOVA analysis between the groups.

$\mathrm{P}$-value for $\mathrm{IL}_{8^{-}}<0.0001$-Significant

Post Hoc; Dunnett-T test for $\mathrm{IL}_{8}$ Group A - C, P-value 0.001 - Significant

B - C, P-value $<0.0001$ - Significant

Table-05: Quantitative analysis; salivary detection of cytokines $\mathrm{IL}_{6} \& \mathrm{IL}_{8}$ by ELISA

In group 'A', HPV-16 was detected in $3(8.6 \%)$ cases while HPV18 was not detected in any of the participants. In group 'B', HPV16 was detected in 07 (20\%) while HPV-18 was detected in 06 (17.1\%) cases. Mixed HPV-16 and HPV-18 were found in 02 (5.7\%). In group 'C', HPV-16 was detected in 03(8.6\%) participants while HPV-18 was not detected in any of the subjects.
Statistical analysis was performed to compare the qualitative relationship between the groups by using Pearson Chi-Square test. The relationship of salivary HPV-16 detection was not found significant between the groups (P-0.245) while the relationship of HPV-18 detection was found significant (P-0.002). (Table-6)

\begin{tabular}{|l|l|l|l|l|l|}
\hline $\begin{array}{l}\text { S. } \\
\text { No }\end{array}$ & Genotypes & Group 'A' & Group 'B' & Group 'C' & Total \\
\hline 1. & HPV-16 & $03(8.6 \%)$ & $07(20 \%)$ & $03(8.6 \%)$ & $13(12.4 \%)$ \\
\hline 2. & HPV-18 & Nil & $06(17.1 \%)$ & Nil & $06(5.7 \%)$ \\
\hline 3. & $\begin{array}{l}\text { Mixed* } \\
(\text { HPV 16 \& 18) }\end{array}$ & Nil & $02(5.7 \%)$ & Nil & $02(01.9 \%)$ \\
\hline \multicolumn{2}{|l|}{ Total } & $\mathbf{0 3 ( 8 . 6 \% )}$ & $\mathbf{1 5}(\mathbf{4 2 . 9 \% )}$ & $\mathbf{0 3}(\mathbf{8 . 6 \%})$ & $\mathbf{2 1}(\mathbf{2 0 . 0 \% )}$ \\
\hline
\end{tabular}

* Both inclusive

Pearson Chi Square analysis between the groups

P- value for HPV-16, 0.245 - Not significant

P- value for HPV-18, 0.002 - Significant

Table-06: High-risk human papilloma virus-16 \&18 detected by Real-time PCR

\section{DISCUSSION}

Salivary detection of $\mathrm{IL}_{6}$ and $\mathrm{IL}_{8}$ levels can serves as potential biomarkers for screening and early detection. This may provide prognostic benefits in terms of survival, quality of life, monitoring treatment outcomes and can serve as a tool for planning strategies for future novel treatment plan of targeted anti-leukotriene therapy (Wong, 2006; Warnakulasuriya, 2009). One can argue that higher levels of salivary cytokines may be the result of an innocent or benign epithelial discontinuity lesion and surrounding inflammation, not directly related to PML or OSCC.

Although gingival or periodontal conditions were not standardized in context of present study, it over-weighs any potential contribution of these cytokines from other sources as these are predominantly produced by the tumour cells and lymphocytes infiltrating the area. Our findings are in close conjunction with the studies reported in literature (Ravindran, 2012; Arellano-Garcia, 2008).
Studies demonstrated that $\mathrm{IL}_{6}$ levels play a pivotal role in suppression of host immune response to prevent neoplastic change. It promotes angiogenesis and lymph-angiogenesis. It also suppresses the $\mathrm{IL}_{8}$ response, thus promoting tumour growth and progression. Studies reported significantly higher salivary concentration of $\mathrm{IL}_{6}$ in OSCC cases compared to normal control (Katakura, 2007; Campisi, 2009). Researchers found increases salivary levels of $\mathrm{IL}_{6}$ and $\mathrm{TNF} \infty$ in patients with oral leukoplakia and postulate that alteration in these cytokines may play a significant role in development of oral leukoplakia (Boy, 2006). Other studies co-related high levels of salivary and serum $\mathrm{IL}_{6}$ with the grade of tumor and found that it is reduced after effective treatment with surgery, radiotherapy, chemotherapy or combination. They considered high level of salivary $\mathrm{IL}_{6}$ concentration is a bad prognostic factor in terms of treatment out comes (Duffy, 2008; Ahluwalia, 2005). 
The results of salivary $\mathrm{IL}_{6}$ levels in our study are at odds with the findings of the majority of the published reports in literature. In present study salivary $\mathrm{IL}_{6}$ levels were not found significantly raised in oral PML and OSCC cases. This may probably attributed to low incidence of cervical nodal and distant metastasis in our study in context of its pro-angiogenetic and lymph-angiogenetic functions. $\mathrm{IL}_{8}$ levels promote tumor suppression and have anti tumor activity through various extracellular and intracellular pathways. Studies reported significantly raised $\mathrm{IL}_{8}$ concentration in OSCC at a cut off value of $600 \mathrm{pg} / \mathrm{ml}$. These workers inferred that elevation of $\mathrm{IL}_{8}$ concentration both at protein and mRNA levels can discriminate inflammatory oro-dental disease like gingivitis and periodontitis from OSCC.

Found high expression of salivary $\mathrm{IL}_{8}$ and $\mathrm{IL}_{1}$ beta levels in OSCC cases (Syrjänen, 1982; Khan, 2007). Another study found that multiplexed assay of both $\mathrm{IL}_{8}$ at protein and mRNA levels measured by electro-chemical sensor have significant difference between OSCC and controls and inferred that these results were closely matching the data measured by traditional assay, using saliva samples(Shah, 2011). A research team found increased salivary concentration of $\mathrm{IL}_{8}$ and higher serum levels of $\mathrm{IL}_{6}$ in patients with OSCC. They did not considered gingival or periodontal conditions as a possible source of these cytokines. According to them their findings overweigh any potential background contribution from host's potential inflammatory conditions (Arellano-Garcia, 2008). We observed the same logic in our study.

Variability observed in these biochemical parameters may be attributed to different life styles, distinct geographic regions, ethnicity genetic differences, and indulgence in peculiar habits. In our study salivary levels of $\mathrm{IL}_{8}$ were detected in majority of the cases and were found consistently raised in oral PML and OSCC. These findings are in close concordance with the reported studies. Inspite of contradicting heterogenecity of the results, one can elute that there is a definite alteration in cytokine production in cases of OSCC which is reflected as altered concentration of at least one pro-inflammatory cytokines in saliva as is the situation in present study.

The role of high-risk oncogenic HPV in oral PML and OSCC has been an issue of extreme controversy. Most controversial issues relating to role of HPV in OSCC are frequency of HPV, viral load acquisition through oro-genital route or otherwise and its diagnostic methodology (Zygogianni, 2011). Substantial evidences exist in literature that high risk HPV-16 and 18 are associated with oral, laryngeal and other head and neck cancers but conflicting data has been reported regarding its prevalence. Its prevalence reported in OSCC vary from <5\% to $100 \%$ (Gichki, 2012; Chaudhary, 2010).

Modes of transmission of HPV in head and neck mucosal districts have not been fully resolved. Orogenital contact, sexual and perinatal transmission specially with oral sex, multiple sex partners and possibly mouth to mouth transmission as in kissing had been implicated (Kulkarni, 2011). It is believed that oral sex, including fellatio and cunnilingus, is the main mode of transmission of HPV infection to oral cavity (Zygogianni, 2011). In the west, HPV is one of the most common viruses transmitted by sexual behaviours in both males and females. In many Muslim dominated countries including Pakistan, religious and socio-cultural values strictly discourage sexual perversions and promiscuity. Therefore immunity from sexually transmitted HPV infection is taken for granted.

In Pakistan, HPV screening for both OSCC and cervical cancer is not commonly practiced due to socio-cultural reasons that prohibit asking enquiries related to oral sex and multiple partners. Therefore the data relating to acquisition of HPV infection is grossly deficient. The gravity of the situation is further aggravated due to stigmas attached to privacy of sexual practices (Marur, 2010; Siribang-on, 2008). This is the major barrier for epidemiological surreys related to HPV incidence and prevalence in Pakistan. As the sexual non-promiscuity in our society could well be a myth, so the knot is still tied relating to association of HPV in OSCC. In the present study, we faced the same barrier, consequently, enquires related to risk factors for acquisition of viral load were not included in data collection performa.

Etiological role of HPV in head and neck carcinogenesis was first proposed by Syrjanen et al in 1983 (Esquenazi, 2010). Subsequently, several studies have supported it on the basis of well proved epitheliotropic nature of HPV, morphological similarities between oral and pharyngeal mucosa with genital epithelium and strongly established role of high risk HPV in cervical cancer (Spielmann, 2011; Zygogianni, 2011; Bhurgri, 2005).

HPV detection was investigated in normal subjects separately or along with PML and / or OSCC groups as control. In a study from Quetta, the capital city of Baluchistan province of Pakistan reported detection rate of HPV DNA in $24.5 \%$ (47/200) in a group of Pakistani subject visiting the dental department having normal oral cavity. They used oral tissue scraping for DNA detection by Real-time PCR method. Out of 47 HPV-positive cases, 4(2\%) contained HPV-16 and 11(6\%) contain HPV-18 genotypes. These results does not co-relate with our findings.

A study was reported from Karachi, Pakistan on the molecular analysis of HPV detection in tissue blocks by Dot Blot and in-situ hybridization and PCR method. They found $17.7 \%$ cases of OSCC positive for HPV-16 \& 18 DNA on PCR and $14.6 \%$ cases showed viral DNA by NISH. They concluded that high risk HPV-16 \& 18 has contributing co-factor role rather than mandatory causative role in oral carcinogenesis (Marur, 2010).

In a study from Allahabad, India reported HPV detection rate of $27.4 \%$ in SMF while it was detected in $31.53 \%$ cases of OSCC on brush biopsy specimen by Hybrid Capture II test. PCR was done on the same specimen for the detection of E6 DNA of HPV-16. They found detection rate of 25.96 in SMF cases and 32.43\% in cases of OSCC. ${ }^{34}$ Same group from India reported high risk HPV detection rate of $31.42 \%(33 / 105)$ in oral PML (OSF) by Hybrid capture II test. Our findings in OSCC cases is quite close to Allahabad study but the findings in oral PML (OSF) does not corelate. Another study from Karnataka, India found salivary detection rate of $54.2 \%$ for HPV-18 in OSCC cases. They reported multiple mixed HPV infection in $4.18 \%$ cases of OSCC in India. These finding are in accord to our study.

Significant association is reported in OSCC with HPV-16 and to a lesser extent with HPV-18.In the salivary samples HPV-16 was the most detectable virus reported in the literature. Low copy numbers 
of HPV was found in the oral PML in the previous studies. These findings are in conjunction with our study.

There are wide differences in the findings of different studies, so it is difficult to compare various published data on HPV association. Possible reasons of this disparity is variation in parameters studied such as type of samples (biopsy tissue, scraping, oral rinse or saliva), preparation method (fresh, frozen or fixed), type of molecular assay employed for DNA extraction, sensitivity of the methodology employed, status of the disease, ethnic and geographical differences in genetic, environment, social, cultural and sexual habits of the population studied (Brinkmann, 2011; Jamee, 2009).

Comparing various studies, the results are highly variable and controversial. No clear cut association or relation of HPV infection with oral PML and OSCC has so far emerged. Our findings are consistent with many of the reported studies. We are unable to support definitive causative or mandatory initiator role of HPV in oral carcinogenesis in our etiologically distinct population where use of areca nut and chewable tobacco is very prevalent in the society.

The present study is believed to be the first of its kind in Pakistan that investigated biomarkers of oral PML \& OSCC in saliva. This unprecedented study would spark new avenues for research in saliva based diagnosis. Considerable excitement exists to envision saliva based diagnosis of oral cancer as a clinical reality in our etiologically distinct population.

\section{CONCLUSION}

Absence of significantly raised levels of salivary $\mathrm{IL}_{6}$ in cases of OSCC, in our region may possibly attributed to lower incidence of cervical nodal metastasis and absence of distant metastasis even at advance stage in context of its pro-angiogenetic and lymphangiogenic function. In this study higher levels of salivary $\mathrm{IL}_{8}$ were more pronounced in cases of OSCC that suggests diagnostic role of salivary $\mathrm{IL}_{8}$ levels as biomarker for oral carcinogenesis

Host response of HPV infection for the causation of oral cancer cannot be fully established possibly due to small sample size. Our study is unable to support definite causative or mandatory initiator role of HPV infections in oral carcinogenesis. It may have a cofactor role rather than just a passenger virus. It is difficult to provide suggestion or recommendation for routine salivary screening for presence of HPV infection in absence of distinct risk habits due to social, cultural, religious and economic constrains.

\section{REFERENCES}

- $\quad$ Ahluwalia, K. P. (2005). Assessing the oral cancer risk of South-Asian immigrants in New York City. Cancer, 104(12), 2959-2961.

- Anaya-Saavedra, G., Ramírez-Amador, V., IrigoyenCamacho, M. E., García-Cuellar, C. M., Guido-Jiménez, M., Méndez-Martínez, R., \& García-Carrancá, A. (2008). High association of human papillomavirus infection with oral cancer: a case-control study. Archives of medical research, 39(2), 189-197.

- $\quad$ Arellano-Garcia, M. E., Hu, S., Wang, J., Henson, B., Zhou, H., Chia, D., \& Wong, D. T. (2008). Multiplexed immunobead-based assay for detection of oral cancer protein biomarkers in saliva. Oral diseases, 14(8), 705-712.

- Bhurgri, Y. (2005). Cancer of the oral cavity-trends in Karachi South (1995-2002). Asian Pac J Cancer Prev, 6(1), 22-26.

- Bhurgri, Y., Bhurgri, A., Hassan, S. H., Zaidi, S. H. M., Rahim, A., Sankaranarayanan, R., \& Parkin, D. M. (2000). Cancer incidence in Karachi, Pakistan: first results from Karachi cancer registry. International journal of cancer, 85(3), 325-329.

- Boy, S., Rensburg, E. J. V., Engelbrecht, S., Dreyer, L., Heerden, M., \& Heerden, W. (2006). HPV detection in primary intra-oral squamous cell carcinomas-commensal, aetiological agent or contamination? Journal of oral pathology \& medicine, 35(2), 86-90.

- Brailo, V., Vucicevic-Boras, V., Lukac, J., Biocina-Lukenda, D., Zilic-Alajbeg, I., Milenovic, A., \& Balija, M. (2012). Salivary and serum interleukin 1 beta, interleukin 6 and tumor necrosis factor alpha in patients with leukoplakia and oral cancer. Medicina oral, patología oral y cirugía bucal, 17(1), 10-15.

- Brinkmann, O., Kastratovic, D. A., Dimitrijevic, M. V., Konstantinovic, V. S., Jelovac, D. B., Antic, J., \& Wong, D. T. (2011). Oral squamous cell carcinoma detection by salivary biomarkers in a Serbian population. Oral oncology, 47(1), 51-55.

- Campisi, G., \& Giovannelli, L. (2009). Controversies surrounding human papilloma virus infection, head \& neck vs oral cancer, implications for prophylaxis and treatment. Head \& neck oncology, 1(1), 1-8.

- Chaudhary, A. K., Pandya, S., Mehrotra, R., Bharti, A. C., Singh, M., \& Singh, M. (2010). Comparative study between the Hybrid Capture II test and PCR based assay for the detection of human papillomavirus DNA in oral submucous fibrosis and oral squamous cell carcinoma. Virol J, 7, 253.

- Duffy, S. A., Taylor, J. M., Terrell, J. E., Islam, M., Li, Y., Fowler, K. E., \& Teknos, T. N. (2008). Interleukin-6 predicts recurrence and survival among head and neck cancer patients. Cancer, 113(4), 750-757.

- Gichki, A. S., Buajeeb, W., Doungudomdacha, S., \& Khovidhunkit, S. O. (2012). Detection of human papillomavirus in normal oral cavity in a group of Pakistani subjects using real-time PCR. Asian Pac $J$ Cancer Prev, 13(5), 2299-304.

- Jamee, M. S., Boorghani, M., Ghaffari, S. R., AtarbashiMoghadam, F., \& Keyhani, A. (2009). Human papillomavirus in saliva of patients with oral squamous cell carcinoma. Med Oral Patol Oral Cir Bucal, 14(10), 525-528.

- Jemal, A., Siegel, R., Xu, J., \& Ward, E. (2010). Cancer statistics, 2010. CA: a cancer journal for clinicians, 60(5), 277-300.

- Katakura, A., Kamiyama, I., Takano, N., Shibahara, T., Muramatsu, T., Ishihara, K., \& Shouno, T. (2007). Comparison of salivary cytokine levels in oral cancer patients and healthy subjects. The Bulletin of Tokyo Dental College, 48(4), 199-203.

- $\quad$ Khan, S., Jaffer, N. N., Khan, M. N., Rai, M. A., Shafiq, M., Ali, A., \& Ali, S. H. (2007). Human papillomavirus subtype 16 is common in Pakistani women with cervical 
carcinoma. International journal of infectious diseases, 11(4), 313-317.

- $\quad$ Kulkarni, S. S., Vastrad, P. P., Kulkarni, B. B., Markande, A. R., Kadakol, G. S., Hiremath, S. V., ... \& Gai, P. B. (2011). Prevalence and distribution of high risk human papillomavirus (HPV) Types 16 and 18 in Carcinoma of cervix, saliva of patients with oral squamous cell carcinoma and in the general population in Karnataka, India. Asian Pac J Cancer Prev, 12(3), 645-8.

- $\quad$ Marur, S., D'Souza, G., Westra, W. H., \& Forastiere, A. A. (2010). HPV-associated head and neck cancer: a virus-related cancer epidemic. The lancet oncology, 11(8), 781-789.

- $\quad$ Mehrotra, R., Gupta, A., Singh, M., \& Ibrahim, R. (2006). Application of cytology and molecular biology in diagnosing premalignant or malignant oral lesions. Molecular cancer, 5(1).

- Ravindran, R., \& Deepa, M. G. (2012). Salivary tumour markers in oral cancer: brief review. Oral Maxillofac Pathol J, 3, 238-243.

- $\quad$ Sato, J., Goto, J., Murata, T., Kitamori, S., Yamazaki, Y., Satoh, A., \& Kitagawa, Y. (2010). Changes in saliva interleukin-6 levels in patients with oral squamous cell carcinoma. Oral Surgery, Oral Medicine, Oral Pathology, Oral Radiology, and Endodontology, 110(3), 330-336.

- $\quad$ Shah, F. D., Begum, R., Vajaria, B. N., Patel, K. R., Patel, J. B., Shukla, S. N., \& Patel, P. S. (2011). A review on salivary genomics and proteomics biomarkers in oral cancer. Indian Journal of Clinical Biochemistry, 26(4), 326-334.

- $\quad$ Siribang-on, P., Buajeeb, W., Sanguansin, S., Poomsawat, S., \& Weerapradist, W. (2008). Detection of human papillomavirus in oral squamous cell carcinoma, leukoplakia and lichen planus in Thai patients. Asian pacific journal of cancer prevention, 9, 771-775.

- $\quad$ Spielmann, N., \& Wong, D. T. (2011). Saliva: diagnostics and therapeutic perspectives. Oral diseases, 17(4), 345-354.

- $\quad$ Syrjänen, K. J., Pyrhönen, S., \& Syrjänen, S. M. (1982). Evidence suggesting human papillomavirus (HPV) etiology for the squamous cell papilloma of the paranasal sinus. Archiv fur Geschwulstforschung, 53(1), 77-82.

- Warnakulasuriya, S. (2009). Global epidemiology of oral and oropharyngeal cancer. Oral oncology, 45(4), 309-316.

- Wong, D. T. (2006). Towards a simple, saliva-based test for the detection of oral cancer. Expert Rev. Mol. Diagn, 6(3) 267-272.

- Zygogianni, A. G., Kyrgias, G., Karakitsos, P., Psyrri, A., Kouvaris, J., Kelekis, N., \& Kouloulias, V. (2011). Oral squamous cell cancer: early detection and the role of alcohol and smoking. Head Neck Oncol, 3(2), 1-12. 